\title{
DURKHEIM Y LA MORAL, UN POSITIVISMO EN TRANSICION
}

\author{
Félix Ovejero Luca
}

\section{UNA «ANOMALIA» EN LA HISTORIA DEL POSITIVISMO}

Una de las mayores dificultades con la que se encuentran los historiadores de la tradición positivista es la de incluir, como «intuitivamente» parece conveniente, bajo un mismo rótulo a los «dos» positivismos que tienen su inflexión en los años primeros del presente siglo: el positivismo «filosófico» y ei positivismo "cientifico». La raiz de tal dificultad hay que buscarla en el cambio de género literatio que se produce al convertirse una tradición de pensamiento que nace como "concepción del mundo", como sus componentes utópicos e incluso religiosos, ${ }^{1}$ en una epistemología a la que repugnan «las escuelas de pensamiento» ${ }^{2}$ y que se avergïenza hasta

1. Hasta el punto de disponer de un «Catecistno» como el escrito por Comte, con sus prescripciones de lectura incluso; hay traducción castellana: Catecismo Positivista, Madrid, 1982 (e.o. 1852). W. M. Simon ha documentado ese estilo del positivismo clásico que «es más que un método: es un sistema de afirmaciones, una concepción del mundo y del hombres, European Positivism in the Nineteentb Century, Nueva York, p. 4.

2. Uno de los fundadores del Círculo de Viena recuerda cómo Schilo «se vio profundamente perturbado por haber otiginado otra "escuela de pensamiento" ${ }_{1: \text { : Her- }}$ bert Feigl, «Origen y espíritu del positivismo lógico», Teorema, vol. IX/3-4, 1979, p. 325. Cuando en 1944, desde las páginas del Mind, W. T. Stace caracterice el positivismo, lo hará en unos términos que delatan tanto la despreocupación por su «pasado» como su conversión en filosofía de la ciencia: "Hay sin duda muchas fllosofías que, a pesar de diferir unas de otras en distintos aspectos, pueden ser propia- 
tal punto de su pasado que se siente en la necesidad de reesctibirlo para que le resulte tolerable. ${ }^{3}$

No es esta la ocasión de rastrear los rasgos comunes de los «dos positivismos», rasgos que existen, aunque no siempre se acierte a la hora de describirlos. ${ }^{4}$ Menos complicado es el rastreo de las diferencias; no son sino los corolarios de la mencionada tectificación de género literario: el abandono de la argumentación moral -que se presentaba en el positivismo clásico revestida de cientificismo- y la acotación al dominio de la reffexión epistemológica de todo ejercicio de la razón no estrictamente científico. ${ }^{5}$

mente llamadas, en un sentido u otro, positivistas. En este artículo intento explicar qué entiendo por positivismo. La característica, desde el positivismo, para que un término tenga significado, es algo parecido a esto: "Un conjunto de palabras expresan una proposición, 'p', significativa sólo si es posible deducir de ella, en combinación con otras premisas, una proposicion o más (al menos una) $Q_{1}, Q_{2}, Q_{3} \ldots$, etc., la verdad o falsedad de las cuales es posible verificar por observación directa. Si las deducciones de ' $\mathrm{p}$ ' verificables no son posibles, entonces lo expresado por ' $\mathrm{p}$ ' es no-significativo, y 'p' no es una proposición, sino una pseudo-proposición." Llamo a éste el Principio Positivista [subrayado W. T. S.], y a toda flosoffa que la sostenga como positivista»: W. T. Stace, «Positivism», en Mind, núm. 211, jułio 1944, p. 215.

3. A. Giddens, quien se ha ocupado en repetidas ocasiones de la tradición positivista, ha recordado Ia casi institucionalizada costumbre del positivismo del siglo $\mathrm{xx}$ de edistinguir entre dos Conte: el autor de la Filosofía Positiva, el serio analista de la historia y del método científico, y el creador de la estrafalaria utopía de la Política Positiva: «Positivism and its critics», en Studies in Social and Political Theory, Londres, 1977 , p. 29. Esta distinción entre los dos Comtes, ya muy tempranamente la "recordó» J. S. Mili, en su ensayo sobre Comte y el positivismo (Madrid, 1977, e.o. 1865), cuya segunda parte, la dedicada a la «Política Positiva», Heva por título: «Las especulaciones de Comte», pp. 149 ss. Ensayo que «debe» bastante -entre ello esta distinción- al del discípulo más direcro -y polémico- de Comte, Littré: A. Conte, et la Pbilosopbie Positive, París, 1862.

4. Las descripciones son casi tantas como historiadores tiene la tradición, con la curiosa circunstancia de que en ocasiones la nómina de Ios autores incluidos no responde a los requisitos estipulados por el propio historiador, especialmente cuando se compromete con tesis gnoseológicas «duras» (nominalismo o realismo), como es el caso de L. Kolakowski, La filosofía positivista, Madrid, 1979.

5. $Y$, si se quiere ser más preciso en lo que respecta a las tesis epistemológicas, el compromiso con el monismo metodológico de las ciencias. El problema empieza a partir de ahí, pues, a la hora de determinar en qué consiste ese «método» que comparten las distintas ciencias, no hay acuerdo sobre hacia dónde se ha de mirar, más altá de la vaga generalización que alude a «las ciencias naturales». Pero a poco que se ahonda en la historia de éstas - labor escasamente frecuentada por los historiadores de la filosofía- se percibe que las creencias metacientíficas de Galileo, Newton, Darwin, Faraday o Maxwell (pot no entrat en la crisis de fundamentos de la transición al siglo $\mathrm{xx}$ ) poco o nada tienen en común entre sf́. 


\section{¿DONDE SITUAR A DURKHEIM?}

Durkheim está situado biográficamente en la transición entre los «dos» positivismos. Nace en 1858 , al año siguiente de la muerte de Comte, hacia el que siempre reconocezá Ias deudas intelectuales de la sociología $-\mathrm{y}$ por lo tanto de su propia obra- por haber introducido la noción fundamental de ley en el ámbito de lo social. ${ }^{6}$ Pero esta deuda no se hará extensiva a la «cosmovisión» positivista; Dutkheim será siempre un equilibrado sociólogo apegado estrictamente al estudio de la sociedad y que se mantendrá alejado de polémicas de claro cuño comtiano, como la que ocupará montones de páginas en las revistas francesas hasta casi los años veinte en torno a la «moral positiva». ${ }^{7}$ En noviembre de 1917, en Fontainebleau, muere Durkheim. Siete años antes de ese —n palabras de Popper referidas a sí mismo- "año crucial»" había comenzado a sutgir en Viena un movimiento que a partir de la epistemología de Mach forjaría los rasgos básicos de lo que sería el positivismo «moderno», el positivismo lógico (o, desde otra perspectiva, escéptico). Durkheim había sido testigo de las circunstancias intelectuales (la crisis de fundamentos de Ia física) y materiales (el colapso del imperio austro-húngaro, la primera guerra mundial) que propiciarían el «tono» de aquel movimiento. En Francia los trabajos de fundamentación de la mecánica de Mach tenían notables continuadores (Poincaré, Duhem, Ie Roy) y no es extraño que Durkheim — no sin cierta tosquedad filosófica, todo hay que decirlo- acuse recibo - crítico- de sus tesis. ${ }^{10}$ Sin embargo, a pesar de sus diferencias, el aceptar el terreno de la

6. En 1903, en un artículo escrito en colaboración con Paul Fauconnet, reconocía Durkheim esas deudas: de un lado, la extensión, frente al dualismo de raíz religiosa y metafísica, de «la idea de las leyes naturales a los fenómerios humanos»; de otro la afimación de la existencia de «leyes propias, específicas, comparables a las físicas - biológicas pero no reducibles a éstas»: É. Durkhein, «Socioloģie et sciences sociales», Revue Pbilosophique, núm. 55, en Textes, 1. Elements d'une theorie sociale, París, 1975, pp. 121-159.

7. De la que es testimonio la inacababie «En quête d'une morale positive» por parte de Gustave Belot desde las páginas de la Revue de Métaphysique et de Morale, vol, 13, 1905, pp. 39.74, 561-88, 728.63; la búsqueda continúa en números sucesivos de la revista que no he podido localizar.

8. «El mundo en que yo había crecido había quedado destruido»: Búsqueda sitt término, Madrid, 1977, pp. 43 y 44.

9. R. Ramos en su introducción a E. Durkheim, El socialismo, Madrid, 1982 (curso dictado entre 1895 y 1896), ha mostrado con minuciosidad la traducción que tienen en su obra $-\mathrm{y}$ en la del adurkheimianismon- las dimensiones históricas, largas (la desintegtación social asociada al capitalismo) y cortas: «la III República en el espacio de tiempo que va desde su creación hasta la I Guerra Mundial», pp. 9-96.

10. Pragmatisme et sociologie, Curso de 1913-14 en la Sotbonne, teconstruido por apuntes po: A. Cuvillier, París, 1955. 
epistemología como el único campo de batalla filosófico, así como -y sobre todo- el que su única obra importante no estrictamente científica sea Las Reglas del Método Sociológico, son buenas muestras de la modernidad del positivistno durkheimiano.

Esta vocación metodológica obligaría a situar a Durkheim a este lado de la historia, junto al positivismo que resignadamente acepta la exclusión del pensar racional acerca de la sociedad si no viene revestido de $\longrightarrow$ mejor, si no queda limitado a - cientificidad. No es tampoco la presente la ocasión de desentrañar las ideas metodológicas del sociólogo francés, se tatata de un asunto conocido. ${ }^{1 \$}$ Más interés tiene el repaso de sus opiniones en la otra materia que está también en el corazón de la inflexión positivista, el tema de la moralidad, o, para decirio con la malsonante fórmula habitual, el tema de los juicios de valor. A la vista de estas opiniones - poco conocidas, a diferencia de lo que sucede con Weber- hay razones para dudar de la «modernidad» de su positivismo, tantas como para mostrarlo como paradigma de una contradictoria y casi tortuosa transición.

11. El haber escrito Durkheim un texto específicamente metodológico, Las Reglas del método sociológico, ha «resuelto» bastante el problema de las interpretaciones; aun así se han producido polémicas que demuestran que no existe un pleno consenso en torno a sus ideas metodológicas, polémicas que, eso sí, han girado en torno a problemas puntuales, como por ejemplo en torno a la importancia de la explicación historica (G. Davy se ha ocupado, no sin contracticciones, de este asunto en su introducción a $E$. Durkheim, Montesquieu et Rousseau, précurseurs de la sociologie, París, 1966 (se trata de dos textos de 1892 y 1918), p. 23, y en su artículo «L'explication sociologique et le recours à I'histoire d'après Comte, Mill et Durkheim», Revue de Métaphysique et de Morale, vol. LVIII, núm. 3-4, 1949, p. 357). Quizá la única polémica de cierta resonancia — más por la importancia del protagonista que por la solidez de sus argamentos-, y que afecta a aspectos más generales, es la que levantó $T$. Parsons en La estructura de la acción social (Madrid, 1968, vol. I, pp. 386-87) al sostener que se produce una transición desde el positivismo originario de Durkheim hasta el idealismo. Pero lo cierto es que, como escribe Whitney Pope, «la interpretación de Parsons refleja mejor su propia actitud teórica que la de Durkheim»: «Parsons' interpretation of Durkheim», American Sociological Review, 1973, vol. 38, núm. 4, p. 400. R. A. Nisbet, «con todos los respetos hacia su posición [la de Parsons]» cree que no existe tal discontinuidad, sino nuevos dominios desdie donde sostener ias ideas originatias, The Sociology of Emile Durkbeim, Nueva York, 1975, pp. 50-51. De hecho, Patsons, cuando no se ve en la necesidad de legitimar sus tesis en base a antecedentes glotiosos, cuando se ocupa estrictamente de hacer historia, no insiste en «su interpretación», como lo demuestra su trabajo sobre Durkheim en la Enciclopedia de las Ciencias Sociales, aparecido como introducción a la edición inglesa de Sociologie et Pbilosophie, Nueva York, 1974, pp. Xlmi-LXX. 


\section{LAS DIVERSAS RELACIONES DE DURKHEIM CON LOS VALORES}

A pesar de escribir no pocas veces la palabra «moral», son escasas las páginas que Durkhein dedica al clásico problema de los juicios de valor. $\mathrm{Y}$ no es paradoja esta desigual distribución, sino un buen indicador de la necesidad de deslindar varios planos antes de quedarse finalmente con el que aquí interesa: la presencia de los juicios de valor en la metodología durkheimiana, los aspectos «internalistas» de su relación. Justo es reconocer que sobre todo en materia de valoraciones no siempre es fácil -aunque sí posible y por tanto conveniente- establecer la dematcación entre lo interno y lo externo. En Durkheim se pueden señalar al menos dos ámbitos previos al que nos ocupa, donde lo mínimo que se puede decir es que las valoraciones, o más llanamente, las ideas políticas, inciden en su obra.

Desde un plano político-cultural es nota obligada reseñar tanto su "diálogo» con el socialismo como el impacto que sobre él produjo $-\mathrm{y}$ que también tuvo su traducción impresa- la Primera Guerra Mundial.". Seguramente no es ajena a ambas circunstancias, ni a su condición de nativo de un país sabio en revoluciones, su preocupación permanente -que atraviesa todas sus obtas importantes, como ha subrayado Zeitlin- ${ }^{13}$ por la función integradora de la moralidad. De hecho Durkheim acuñó bastantes conceptos (consciencia colectiva, anomia, solidaridad orgánica, solidaridad mecánica, etc.) que apuntan a tal preocupación.

Otra perspectiva, más cetcana a problemas epistemológicos, la propotciona el acercarse a las dificultades con que tropieza un autor como Durkheim, "sensibilizado» - sea por tazones de nómina o de fondo- para con la política, como muestran los ejemplos anteriores, y a la vez tributatio de una idea de razón, la positivista de todos los tiempos, para la que todo ejercicio de la misma - y mal que pese a aquélla, la política, tiene algo que

12. E. Durkheim, El socialismo, op. cit.; asimismo, «Internationalisme et lutte des classes», en La sciencie sociale et l'action, París (e.o. 1906), 1970, pp. 282-92. Véanse los trabajos de Jesús de Miguel, «El otro Durkheim», Papers, núm. 2, 1974, pp. 43.78, y Raymond Aron, «Sociologie et socialisme», en "Centenaire de la Naissance d'Émile Durkheim», Annales de I'Université de Paris, núm. 1, 1960, p. 9. Por lo que respecta al segundo asunto, el impacto de la Primera Guerra Mundial -en ia que Durkheim perdió un hijo-, E. Durkheim, Qui a voulu la guerre? Les origines de la guerre d'après les documents diplomatiques y L'Allemagne au-dessus de tout: la mentalité allemande et la guerre, aparecidas ambas en París, 1915; asimismo, L. Rođriguez Zúñiga, «Duxkheim: su concepción del Estado y la 1. Guerra Mundial», en «Revista Española de Opinión Pública», núm. 32, 1973, pp. 119.53.

13. I. Zeitlin, Ideología y teoria sociológica, Buenos Aires, 1979, p. 273. 
ver con ésta, la razón- que no sea el científico es calificado de insensato. ${ }^{14}$ A esta cuestión responde Durkheim de dos maneras: de un lado - a pro pósito del marxismo - condena la «politiquería» por ser precisamente polí" tica, asî teprocha «a ciettas teorías que se dicen científicas» el que sean subversivas y revolucionarias, peto esto porque sólo son científicas de nombre, pues su doctrina «se detiva de un principio no extraído de la observación de los hechos morales», por lo que «es inevitable que contradiga en más de un punto el orden moral existente» $;{ }^{15}$ de otro, tratará de tesolver estos «asuntos» sin alejarse de los únicos ejercicios de la razón que estima jus. tificados, la ciencia y la epistemología, sobre cuyas bases pretendetá obtener recomendaciones «tecnológicas».

14. Es éste uno de los puntos de continuidad entre los «dos» positivismos, la creencia en que el único tipo de discurso racional es el científico (o el metacientífico), que si en el primer positivismo se traduce en el intento de incluir en la ciencia la resolución de los problemas políticos, en el segundo, más sensato epistemológicamente, más temeroso socialmente y más escéptico moraimente, se traduce en la exciusión al dominio de la sinrazón de la argumentación ético-política: es el mismo Wistgenstein el del Tractatus, el que cree que sobre «lo importante» (la ética, la segunda parte no escrita en el libto, tal y como dice en su correspondencia: A. Janik y S. Toulmin, La Viena de Wittgenstein, Madrid, 1974, p. 274) eno se puede hablar", el que rellena los cuadernos preparatorios de aquelia obra con consideraciones acerca del yo, el libre albedrío, el significado de la vida y la muerte, el atento lector de Schopenhauer (G. Henrik von Wright, en su ensayo sobre el austríaco incluido en J. Ferrater Mora [y otros], La filosofía de Wittgenstein, Barcelona, 1966, p. 29). De esta vertiente mística es de donde intenta huir Durkheim, tanto como de la «Política Positiva» comtiana. El problema es que, a pesar de ello, Durkheim no dejará de ser un «moralista», como lo llama Jean Sarrailh («Allocution», con ocasión del «Centenaire de la naissance d'Émile Durkheim», Annales de l'Université de Paris, 1960, núm. 1, p. 9), sin dejar de suscribir la idea de razón del positivismo.

15. E. Durkheim, De la división del trabajo social, Buenos Aires, 1973 (e.o. 1893), p. 35. No ha de resultar extraño que Aron se encargue de subrayar que Durkheim «ha concebido la sociología como la contrapartida científica del socialismo", art. cit., p. 33. $\mathrm{Y}$ en algún sentido nada trivial, en el reconocimiento de que se trata de un ideario emancipador, no le faita razón a Durkheim cuando escribe que el socialismo marxista «no puede ser científico. No puede utilizar más que ciextos datos incompletos y fragmentarios, al servicio de una causa que sostiene por razones ajenas a la ciencia; porque las rebasa», según escribe en una reseña sobre A. Labriola aparecida en 1897 en la Revue Philosophique, citado por J. M. de Miguel, art. cit., p. 52. Según cuenta $M$. Mauss $-\mathrm{y}$ recoge $\mathrm{I}$. Zeitlin, op. cit., p. 265-, el socialismo le producia disgusto por «su naturaleza violenta, su caxácter de clase - más o menos obrero- y por tanto su tono político y hasta politiqueros. Sobre la relación entre la obra de Marx $\mathrm{i}$ la de Durkheim, A. Cuvilliet, «Durkheim et Marx», Cabiers Internationaux de sociologie, 1948, pp. 75-97; Jeffrey C. Alexander, historiador del positivismo en el primer volumen de Theoretical Logic in Sociology (Positivism, Presuppositions, and Current Controversies, Londres, 1982), dedica el segundo a un análisis, de "estática comparativa", de The Antinomies of Classical Thought: Marx and Durkbeim, Londres, 1982. 
La extrapolación de los principios epistemologicos se realiza de diversas maneras, que tienen, todas ellas, un carácter de precedente, $\mathrm{y}$ de las que aquí sólo recordaremos dos. La primera de ellas recuerda en más de un punto - entre los que se encuentra la tmisma escasez de bondad epistemológica- la «ingeniería social fragmentaria» de Popper; ${ }^{16}$ también Durkheim cree que «un hecho no puede ser modificado sin que éstos (otros hechos) sean alcanzados, y a menudo es muy difícil calcular por adelantado el resultado final de esa serie de repercusiones, así es como el espíritu más audaz se vuelve reservado en cuanto a la perspectiva de semejantes riesgos (...) $\mathrm{La}$ intervención es entonces limitada: tiene como objeto no hacer con un fragmento una moral junto o por encima de la que reina, sino corregirla o mejorarla parcialmentes. ${ }^{17} \mathrm{El}$ mismo tono conservador se detecta en la reflexión que hace a partir de otra cuestión estrictamente epistemológica como lo es la explicación funcional: «Finalmente y sobre todo, todo hecho de orden vital - como lo son los hechos morales- no puede durar a menos que sirva para algo, que responda a alguna necesidad; en tanto que la prueba contraria no se haga, tiene derecho a nuestro respeto. $\gg^{18}$ Basten estos testimonios como muestra - de escasa solidez, ${ }^{19}$ pero no es éste el

16. «El ingeniero fragmentario sabe (...) que sólo podemos aprender de nuesttos ertores. Por tanto avanzará paso a paso $(\ldots)$; y evitará el comenzar por reformas de tal complejidad y alcance que le hagan imposible desenmarañar causas y efectos»: La miseria del bistoricismo, Madrid, 1961, p. 81. Para una crítica de la frágil $-\mathrm{y}$ en algún punto contradictoria con sus propias tesis epistemológicas- argumentación popperiana, M. A. Quintanilla, «Adversus ingenieros (Hacia un replanteamiento de las relaciones entre teoría y acción en las ciencias sociales)m, Cuadernos económicos de ICE, núm. 34, 1977, pp. 248-74.

17. E. Durkheim, De la división..., op. cit., p. 36. Más explícito es en otro lugar: «Nuestras creencias morales son el producto de una larga evolución; ellas resultan de una sucesion de interminables tanteos, esfuerzos, fracasos, experiencias de toda suerte. Como sus orígenes son lejanos, en ocasiones no podemos percibir las causas que los explican. Mientras tanto, debemos someternos respetuosamente, porque sabemos que la humanidad, después del sufrimiento y el trabajo, no ha encontrado nada mejor (...). Sería verdaderamente pueril querer rectificar con nuestro pequeño juicio particular los resultados de la experiencia humana. Sin duda llegará un día en que la ciencia de la moral habrá avanzado lo suficiente para que la teoría pueda regular la práctica: pero todavía estamos lejos $\mathrm{y}$, de momento, lo más sabio es atender las enseñanzas de Ia historia.» E. Durkheim, «La sciencie positive de Ia morale en Allemagne», Revue Pbilosophique, núm. 24, 1887, en Textes, op. cit., pp. 342-343.

18. E. Durkheim, De la división..., op. cit., p. 36.

19. Al no proceder Durkheim con el tosco estilo de Ias utopías comtianas, sino con más sutileza, resulta oportuno y necesario detenerse en el análisis de sus exposi. ciones para mostrar dónde comienzan a aparecer las consideraciones ético-políticas en el marco de sus consideraciones epistemológicas. La falta de solidez de su exposición de ta explicación funcional se hace manifesta en el estilo tautológico con que ésta aparece en Las Reglas: «Si los caracteres cuya concurrencia forma el tipo normal han 
tema- del segundo plano, el de la epistemología, en donde se expresa la relación de la obra durkheimiana con el tema de los valores. Es oportuno subrayar que, si bien no se trata de la telación directa de este asunto con la ciencia, sí busca Durkbeim una fundamentación de las elecciones morales - conservadora en su caso- en consideraciones epistemológicas que a su vez se fundamentan en - los rasgos de- la ciencia. Es en otros trabajos donde se expresa - y con ellos llegamos por fin al tema que nos ocupa-.. Ia trabazón más interna, más integrada en el discurso de la ciencia, del problema de los valores. Problema que se despliega en diversos argumentos.

\section{LOS FINES Y LA «RAZON INSTRUMENTAL»}

A pesar de las anteriores recomendaciones «tecnológicas» sobre la base de las posibilidades del conocimiento de lo social, dista mucho Durkhein de resignarse a reducir la ciencia a esta simple función. Sus críticas a la teotía del conocimiento pragmatista ${ }^{20}$ pueden ser interpretadas como una expresa resistencia a reducir la ciencia a sus funciones prácticas. De todas maneras, sus opiniones no dejan de tener algún punto de ambigüedad no ajeno a su negativa a abandonar la acción a la sinrazón en el marco de una idea de razón apegada tan sólo a la ciencia. Por una parte, reprocha a la economía y la moral que se preocupen de «la forma en que sería bueno» que se encadenaran los hechos y no de aquella en que «se encadenan realmente», ${ }_{2}^{21}$ en suma, que se preocupen del «debe ser» en vez del «es»y

podido generalizarse en una especie, ello no sin motivo (...). Esa generalización sería inexplicable si las formas de organización más extendidas no fuesen también las más avanzadas (...) [Su frecuencia mayor] es por tanto prueba de su superioridad.» Les règles de la métbode sociologique, París, 1973 (e.o. 1895), p. 58. Es decit, los rasgos que definen a las sociedades son los mejores para su supervivencia, esa sociedad es la mejor para ser como es, o dicho de otra manera, lo notmal en esa sociedad es lo que le permite ser normal. Cuaiquier rasgo que sobreviviese se convertiría en un nuevo atributo definidor de la sociedad: irrefutable. El otro argumento, el de la ingeniería social, se apoya en una visión falsa de lo que es el conocimiento científico, éste no conoce hechos sin «totalidades» (estructuras, sistemas: de correos, bancarios, sociales, económicos, etc.), por to que hay buenas razones para que las intervenciones - para controlar todas las tepercusiones, precisamente - recaigan sobre estructuras.

20. E. Durkheim, Pragmatisme..., op. cit., especialmente la «Seizième leçon: Spéculation et Pratique. Les arguments de Dewy en faveur de la subordination de la pensée à l'action», pp. 153-67.

21. Les règles..., op. cit, p. 27. 
que sobre todo, lo oculten, como sucede con la primera, donde las leyes no son sino «preceptos prácticos disfrazados». ${ }^{22}$

Sin embargo, por otro lado, se convierte en un «precursor» de los críticos de la razón instrumental: "Ahora bien, si la ciencia no puede ayudarnos en la selección del mejor fin, ¿cómo podría enseñatnos cuál es el mejor camino para conseguirlo? ¿Por qué iba a recomendar el camino más tápido con preferencia al más económico, el más seguro antes que el más simple, o a la inversa? Si no puede guiarnos en la determinación de los fines superiores, no será menos impotente cuando se trata de fines secundarios y subordinados Ilamados medios.» ${ }^{23}$ Pero también, como los crí. ticos por excelencia de la "tazón instrumental», los francfurtianos, se vetá en la recesidad de falsear la ciencia.

Es obvio que la exposición durkheimiana no debilita un ápice una cuestión: la discriminación entre prescripción y descripción, cuyo corazón es lógico $\mathrm{y}$, por tanto, inatacable. ${ }^{24} \mathrm{~T}$ al vez si hubiese tenido la modestia de donde dice «ciencia» escribir «fllosofía», su argumento - tema permanente de la Política Económica rescatado no ha mucho por Ferrater Mora para su gremio originario- ${ }^{25}$ se viera dotado de mayor verosimilitud. Peto el olmo positivista se proclama orgulloso de su carencia de peras filosóficas. Ahora bien, esto no resta validez al otro aspecto, el más importante, de la crítica durkheiniana a la conversión de las ciencias sociales en simples disciplinas de gestión, cuya cristalización más conocida es la famosa defirición por Robbins de ciencia económica como aquella que «estudia el

22. Ibidem, p. 26. Para las relaciones de Durkheim con ta economía -aunque sin insistir en el extremo aquí subrayado-, G. Aimard, Durkbeim et la science economique, París, 1962.

23. E. Durkheim, Les règles..., op. cit., p. 48.

24. J. Muguerza, en su ya clásico - esto es, que conviene releer- ensayo La razón sin esperanza (Madrid, 1977, pp. $65-96$ y 175-220), muestra pot mil vericuetos la imposibilidad del salto deductivo - por lo demás tan obvio y totundo como los asuntos de la lógica- entre ciencia y moral. La esterilidad de los intentos de pasar del «set» al «deber ser» -en sus distintas versiones: promesas, juicios técnicos, dolor- ha sido argumentada por J. S. P. Hierro, Problemas del analisis del lenguaje moral, Madrid, 1970, cap. IV.

25. Las ideas de que las valoraciones también afectan a los medios (Myrdal) o las de jerarquización de los fines (Seraphin, Watson) han sido y son frecuentes en Ia literatura económica. Véanse a este respecto los repasos de F. Estapé, Fines y Medios de Politica Económica, Departamento de Política Económica de la Universidad de Barcelona, public. núm. 12, o el trabajo de J. Jané Solá, «Por una estructura operativa de Ia Politica Económica», en Revista Española de Economía, enero-abril 1974, vol. 1, pp. 9-44. Ferrater Mora, en De la materia a la razón (Madrid, 1979, pp. 156 y ss.), repite este esquema de fnes superiores, secundarios y subordinados bajo la fórmula de fines «suficientes» y «supersuficientes». 
comportamiento humano como una relación entre fines y medios limitadoss, ${ }^{20}$ esto es, como una tarea ingenieril desinteresada de la obtención de legalidades. Hacia el final de su vida el escepticismo de Durkheim hacia las posibilidades prácticas de la sociología parecía haberse incrementado: «Su función [la del sociólogo] es únicamente determinar bien los hechos que coroprende su estudio, descubrir las leyes según las cuales se producen, dejando a otros el cuidado de encontrar, si ha lugar, las posibles aplicaciones de las proposiciones que establece. $\rangle^{2 n}$

\section{LA FALACIA NATURALISTA EN DURKHEIM}

La tensión en que se debate Durkheim al ocuparse de una disciplina relacionada, más o menos remotamente, con los problemas humanos, el techazo que le producen los «moralistas» de diverso cuño - tecnológico o teológico- $y$, por último, sus débitos para con la razón positivista, tendrán su «solución» a través de una pequeña trampa lógica que le permite

26. Ensayo sobre la naturaleza y significación de la ciencia economica, México, 1980 (e.o. 1932), p. 39. Hay que decir que la visión pragmática de la teoría económica so es privativa de la tradición neoclásica. Aunque en el paradigma clásico-ricardianomarxista-laico hay una vocación explícita de obtener legalidades, entre los marxistas de la mejor calidad, en una tradición que tiene su punto de partida en la obra de D. Lange, se hacen afrmaciones del tipo: "con el tiempo deberá llegar un período en que Ias tesis económicas serán deducidas de un sistema praxeológico maduro, de la postulación de una teoría de la acción eficaz»: T. Kotarbinski, «Praxiología y economías, Problemas científicos y económicos, Suplementos III/7. UNAM, México, 1967, p. 18. Como contrapunto, los marxistas «laicos» con sensibilidad epistemológica se cuidan de precisar que «el economista teórico no es un fontanero ni nada que se le parezca: su misión no es resolver casos prácticos (...). La posición formalista desemboca, en el mejor de los casos, en la tecnología económica, y en el peor, en el embellecimiento ideológico de algún proyecto políticon; A. Barceló, Reproducción económica y medios de producción, Barcelona, 1981, pp. 19 y 21. Durkheim no mantendrá posturas alejadas de éstas -como revela la cita de la nota siguiente-, todo lo más admitirá que «los progresos del arte político seguirán a los de la ciencia social, como los descubrimientos de la fisiología y de la anatomía han ayudado a perfeccionar el arte médicos, «Sociologie et sciences sociales», dentro de la obra colectiva De la Méthode dans les Sciences, Paris, 1920, p. 314. La disociación entre el aspecto estrictamente científico y el práctico es un punto a reconsiderat entre los socíblogos que mitan con cierto complejo la fastuosidad artificiera de los economistas; sobre todo si teparan en cosas como que las predicciones en base a series tempotales - -esto es sin incorporar «teoría»- son en no pocas ocasiones más eficaces que las estrictamente basadas en modelos econométricos («explicativos»), esto es que Ptolomeo tiene más cosas que decir que los presuntos Galileos.

27. E. Durkheim, «Sociologie et...», en De la Metbode dans..., op. cit., p. 308. 
resolver en el marco de su único asidero, la ciencia, lo que, si se es respetuoso con la lógica, demanda de soluciones en el terreno de la práctica. Así se expresa Durkheim: «No hay que olvidar, en efecto, que si hay interés en distinguir lo normal de lo anomal, es principalmente con el fin de iluminar la práctica. Ahora bien, para obrat con conocimiento de causa no basta con saber lo que debemos querer, sino por qué debemos querexlo. $)^{28}$

Durkheim repetirá en más de una ocasión «ese cambio», en palabras de Hume, «imperceptible, pero [que] resulta, sin embargo, de la mayor importancia ${ }^{29}$ y que Moore calificó; en expresión que ha hecho fortuna, como «falacia naturalista» ${ }^{30}$ para referirse a cualquier intento de definir «bueno», pues cualquiera que sea la definición proporcionada siempre tendrá sentido interrogarse sobre si este definiens es bueno; el simple hecho de que sea posible tal pregunta es una prueba de que nos enfrentamos a dos nociones distintas, a saber la «bondad" y el definiens proporcio. nado. Por extensión se calificó del mismo modo cualquier intento de pasar del «es» al «deber ser», entre los que destaca el de J. S. Mill cuando, por analogía con «visible», que significa "capaz de ser visto», no se apercibió de que "deseable» no equivale a «capaz de ser deseado», sino a «debe ser deseado» o «es digno de ser deseado»; en suma y dicho de otra manera, que de ues realmente deseado" no se sigue que sea «deseable».

Esta pequeña excursión por la historia de la falacia naturalista queda justificada porque Durkheim incurritá, una y otra vez, en una y otra forma y en todo tiempo, en la misma. Su argumentación en Las reglas del método sociológico aparecerá imbricada, por las razones antes expuestas, con la necesidad de distinción entre lo normal y lo patológico, pues «para las so. ciedades como para los individuos, la salud es buena y deseablem. ${ }^{31}$ En 1906,

28. E. Durkheim, Les Règles..., op. cit., p. 60. En la presentación del capitu. lo III lo formula con mayot claridad: «Es preciso que sea científcamente posible (la distinción entre lo normal y lo patológico) para que la ciencia pueda servir para la direccion de la conducta.» Ibidem, p. 146.

29. D. Hume, Tratado de la naturaleza bumana, Madiid, 1977, vol. II, pp. 689-90.

30. Véanse los trabajos de C. L. Stevenson, «Argumentos de Moore contra ciertas formas de naturalismo», del propio G. E. Moote, «Réplica a mis críticos», y de W. K. Franikena, «La falacia natutalista», incluidos en Philippa Foot, Teorías sobre la ética, México, 1974, pp. 31.98; todos en torno a la falacia bautizada por Moore en 1903 en Principia Ethica.

31. E. Durkheim, Les règles..., op. cit., p. 49. La siguiente larga cita es una buena muestra de los extremos -intenciones $\mathrm{e}$ instrumentos- de lo expuesto hasta ahora: «Nuestro método tiene además la ventaja de tegular la acción a la vez que el pensamiento. Si lo deseable no es objeto de observación, pero puede ser determinado por alguna suerte de cálculo mental, ningún límite, por decirio así, puede ser asignado a la libre invención de la imaginación que busca lo mejot. Pues tcómo 
tras un comienzo excelente en cuanto a discriminación analítica: «La realidad moral, como todo tipo de realidad, puede ser estudiada desde dos puntos de vista diferentes. Se puede buscar conocerla y comprenderla; o bien se puede proponer juzgatla. El primero de esos problemas es puramente teórico y debe preceder necesariamente al segundo. Éste es el único que se tratará aquí»; tras este comienzo, al exponer las tesis del trabajo, señalará como primera: «Se mostrará como la sociedad es una cosa buena, deseable para el individuo. $\gg^{32}$ Cinco años más tarde su rotundidad es todavía mayor: "Todo lo que tiene valor es bueno en alguna forma; lo que es bueno es deseable; todo deseo es un estado interior. $Y$, por tanto, esos valores tienen la misma objetividad que las cosas. $\rangle^{33}$

Tampoco hay que cargar excesivamente las tintas a la hora de repasar los intentos durkheimianos de hacer «objetivos» los valores. La mayor parte de las proposiciones en que Durkheim incurre en la temible falacia no son sino «trampas del lenguaje» posiblemente salvables mediante algún tipo de reformulación sin que se altere en exceso la tematización de fondo. Pero lo que sí es importante es la tensión que permanece en la base de sus intentos por delimitar «lo normal» de «lo patológico» o de acotar la bondad de la sociedad y el pretender bacerio desde el único argumento racional que reconoce, el científico.

\footnotetext{
asignat a la perfección un término que no puede sobrepasar? Ella escapa por definición a toda limitación. El fin de la humanidad recula entonces hacia el infinito, desanimando a unos por su misma lejanía, excitando, por el contratio, a otros, que para acercarse al mismo un poco aceletan el paso y se precipitan en revoluciones. Se escapa a este dilema práctico si lo deseable es la salud y si ésta es una cosa defnida y dada en las cosas, pues el objetivo del esfuerzo está dado y definido al mismo tiempo. No se trata de perseguir desesperadamente un fin que se aleja a medida que avanzamos, sino de trabajar con persistencia regular para mantener el estado normal, para restablecerlo si ha sido alterado, para reencontrat sus condiciones si éstas se alteran. El deber del hombre de Estado no es el de empujar violentamente las sociedades hacia un ideal que le parezca atractivo, sino que su papel es el del médico que prevé la eclosión de las enfermedades con una buena higiene y, cuando se decla. ran, intenta curarlas.» Ibidem, pp. 7475. Como sucede con la metáfora de la enfermedad, «se supone que la sociedad, básicamente, goza de buena salud; el mal (el desajuste), en principio, siempre puede ser superados: S. Sontano, La enfermedad como metáfora, Barcelona, 1980, p. 119.

32. E. Durkheim, «Determination du fait moral», Bulletin de la Société française de Pbilosopbie, febrero de 1906, incluido en Sociologie et Pbilosopbie, París, 1963, pp. 49 y 53.

33. E. Durkheim, «Jugements de valeur et jugements de réalité», Revue de Métaphysique et de Morale, número excepcional, 3 de julio de 1911, en Sociologie et Pbilosophie, op. cit., p. 119.
} 


\section{JUICIOS DE VALOR Y JUICIOS DE REALIDAD}

En 1911 afrontará Durkheim más directamente el tema de los valores en una comunicación para el Congreso Internacional de Filosofía celebrado en Bolonia. En esta intervención suya, dentro de aquella intención última de retrotraer las valoraciones a la ciencia, tratará de demostrar que "para comprender cómo los juicios de valor son posibles, no basta con postular un cierto número de ideales, hace falta rendir cuentas, saber de dónde vienen, cómo se enlazan con la experiencia y en qué consiste su objetividad» ${ }^{34}$ Con esta intención general distinguitá Durkheim entre dos tipos de juicios de valor, que firralmente, en su opinión, no lo resultarán tanto.

En primer lugar: «Cuando yo digo: me gusta la caza, prefiero la cerveza al vino, la vida activa al reposo, etc., emito juicios que pueden parecer expresar valoraciones, pero que son, en el fondo, juicios de realidad. ${ }^{35}$ No cabe reprochar a Durkheim el que no use las consabidas comillas para saber en qué plano -lenguaje o metalenguaje, la manifestación del deseo o la constatación de eso- se desenvuelve, pero tampoco hay que ocultar que este tipo de juicios, que algunos han convenido en llamar «tesolutivos», no está claro si son juicios acerca de lo que se quiere, en cuyo caso no sería errada la opitión de Dutkheim, o son simplemente expresiones del querer, en cuyo caso su inclusión entre los descriptivos sería harto dif́cili. ${ }^{36}$ En cualquier caso a Durkheim no se le escapa otro de los rasgos de este tipo de juicios, el carácter «incorregible» ${ }^{37}$ de las bases en que se fundamenta su enunciación: «Aquellos que los experimentan, 0 , al menos, que creen experimentarlos; pero no los pueden transmitir a otros. ${ }^{38}$ Seguramente es esta «privacidad» la que le lleva a concentrar sus esfuerzos en el otro grupo de

34. Ibidem, p. 132 ,

35. Ibidem, p. 118.

36. Comentando este tipo de juicios («yo quiero conseguit $X_{\gg}$ ), escribe J. S. P. Hierto (op. cit., p. 147): «Mi opinión actual se inclina en el sentido de considerar a los resolutivos como pertenecientes a un tercer género, distinto tanto de los juicios prescriptivos como de los descriptivos.»

37. Se trata de una «incorregibilidad» bien efímera: «Lo "incorregible" es Ia firmeza de las bases sobre las cuales fundamenté el enunciado, no en el sentido de. que la existencia de ellas no pueda ser negada o cuestionada pot otras personas o por mí mismo en otro momento, sino en el sentido de que, dada su existencia $-y$ es. fundamental para el argumento que me haya sido dada-, entonces, independientemente de toda otra prueba, la verdad del enunciado está perfectamente asegurada. Sólo en este sentido puede considerarse que el enunciado no está sujeto a ninguna prueba ulteriors: A. J. Ayer, El problema del conocimiento, Buenos Aires, 1962, p. 68.

38. E. Durkheim, «Jugements...», art, cit, en Sociologie et Pbilosophie, op. cit., p. 118 . 
juicios de valor, que parecerían tener mayor importancia para el conocimiento científico.

Este segundo grupo incluiría, en su opinión, juicios del tipo: «Este hombre tiene un alto valor moral; esta mesa tiene un gran valor estético; esta joya vale tanto. En todos estos casos, atribuyo a seres o cosas de las que hablo un carácter objetivo. ${ }^{39}$ Independientemente de lo que hay de «analogía confundente», de «embrujamiento de la inteligencia por el lenguaje» (Wittgenstein), en esa asimilación entre los tres usas -bien distintosn de «valor», lo más relevante es el intento, más o menos platónico de Durkheirn de «ontologizar» no sólo los valotes —que existen, que se dan en la sociedad- sino también los juicios de valor: «Admitimos implícitamente que estos juicios cotresponden a alguna realidad objetiva sobre la cual el entendimiento es posible y debe hacerse. Son tealidades "sui generis" que constituyen valores y los juicios de valor son aquellos que se refieren a estas realidades. ${ }^{40}$

Para garantizar la objetividad de tales juicios, Durkheim arguye que no hay diferencia fundamental entre los juicios de valor y los juicios de realidad, y lo bace en una forma que recuerda, para bien y para mal, to que se ha verido en llamar "giro lingüístico»" ${ }^{41}$ de la ética, y que, sumariamente, consiste en el establecimiento de una "comunidad de comunicación» que sobre Ia base de algún tipo de «voluntad general», ${ }^{42}$ que requiere, a

39. Ibidem, p. 118 .

40. Ibidem, p. 119.

41. J. Muguerza ha insistido en las concordancias que entre las distintas tradiciones de pensamiento ha supuesto ese «giro»; véanse, entre otros, sus trabajos: «Filosofía y diálogos, en VVAA, Simbolismo, sentido y realidad, CSIC, Madrid, 1979, pp. 87-117, y «La ética en Ia cruz del presente», en Enrabonar, núm. 1, UAB, Bella. terra (Barcelona), 1981, pp. 7-16.

42. De todas formas esta referencia al «contrato social» distaría mucho de ser unívoca en cuanto a su significación. Cierto es que Rawls señala que «lo tratado de hacer es generalizat y llevar la teoría tradicional del contrato social representada por Locke, Rousseau y Kant a un nivel más elevado de abstracción» (Teoría de la justicia, México, 1979, p. 10); por el contrario, para los francfurtianos, para Habermas en particular, aquella teoría estaría apoyada más sobre ed vínculo negativo del interés» que sobre la idea de razón. De todas formas habría que hacer un par de precisiones al intento de radicalizar estas matizaciones. La primera de orden histórico: no está tan claro que la interpretación de los clásicos por el vínculo del interés sea unívoca, al menos en la línea que une a - -gentes tan dispares como- Rousseau y Fichte con Marx, tal como Io recuerda Kolakowski (Las principales corrientes del marxismo, I, Los fundadores, Madrid, 1980, p. 60). La segunda objeción sería de orden teórico, pues si estamos - -y no vemos cómo no podríamos estarlo- de acuerdo con Mosterin -y una larga tradición filosofica, que cesde luego no empieza en Kant- en que la racionalidad práctica «no tiende a la verdad, sino, en definitiva, a la felicidad», la distinción acentuada por Habermas entre interés y «verdad» (en 
su vez, de una serie de requisitos (análogos, idealizadamente, a los que se dan en las comunidades científicas) capaces de impedir formas de coerción entre los participantes, permita decit "qué es propiamente lo racional»" en materia de valores. Durkheim argumenta de la siguiente manera: "Entre los juicios de valor y los juicios de realidad no existe diferencia de naturaleza; un juicio de valor expresa la relación de una cosa con un ideal. Ahora bien, el ideal está dado como la cosa, es también una realidad a su modo. La relación expresada une los dos términos como en un juicio de existencia. ¿Se ditá que los juicios de valor ponen en juego los ideales? Pero eso también sucede con los juicios de realidad. Pues los conceptos son también construcciones del espíritu, por tanto ideales; y no sería difícil demostrar que también son ideales colectivos, puesto que no pueden constituirse más que por el lenguaje, que es, en el más alto punto, una cosa colectiva. Los elementos de juicio son, pues, los mismos en una parte que en otta. $\rangle^{44}$

Es indudable la sutilidad de la argumentación durkheimiana, sutilidad que no hace sino mostrat el deseo de hacer ciencia de los valores que nutre su obra. Sin embargo, también aquí realiza una pequeña trampa, obligado paradójicamente por su positivismo a ser un mal positivista, pues si bien es cierto que «la corrección de un precepto o proposición puede no depender del consenso, pero la racionalidad de su aceptación sí», ${ }_{3}^{45}$ no deja de tratarse de dos problemas distintos, y en un terreno, el de la telación con el mundo, hay una diferencia radical entre los juicios de hecho y los de valor, por lo que conviene prevenirse contra la exageración -más frecuente ciertamente entre los francfurtianos, pero no extrana a los «juegos del lenguaje» wittgensteinianos-45 que supone el

ética) se hace difícil de sostener; sin que ello nos obligue a suscribir la visión un tanto lobuna de la racionalidad de Mosterín, Racionalidad y acción bumana, Madrid, 1978 , p. 52.

43. I. Habermas, Marcuse, «Teoría y Política», Cuadernos Teorema, Valencia, 1980 , p. 29.

44. E. Durkheim, «Jugements...», art. cit. en Sociologie et Pbilosopbie, op. cit., p. 139.

45. K. Iehrex, C. Wagner, Rational Consensus in Science and Society, Londtes, 1981, p. 7.

46. La doea wittgensteiniana del lenguaje como uso, con su racionalidad interna, encontró un campo abonado para ejercitat «racionalidades» propias de cada «uso» en la filosofía de la religión, con lo que se abandonaba lo más específico de la racionalidad, su vocación de universalidad; y de paso, «lo más característico de la creencia teligiosa en religiones como el cristianismo»: J. Sádaba, Filosofía lógica y religión, Salamanca, 1978, pp. 26-27; véase asimismo la réferencia de A. Fierro a los «juegos del lenguajes en Presentación de la teología, Batcelona, 1980, pp. 25 y ss. 
pensat que «los valores y las normas poseen una referencia inmanente a la verdad» ${ }^{47}$ por más que no se deje de reconocer la plasticidad de las «inmanencias» y las «referencias».

Finalmente parecería que Durkheim, a través de la analogía entre «pensado como verdadero, luego realmente verdaderon y upensado cono deseable, luego realmente deseable», volviese a testablecer, por un nuevo itinerario, la falacia naturalista, olvidando que hay una desanalogía radical entre ambas inferencias, la misma que hay entre lo que «es auténtico para la gente en términos de sus deseos y acciones reales» y el «concepto de "creencia humana correcta" [que] no gira sobre ningún aspecto de Ia postura del hombre respecto del mundo, sino sobre "los hechos reales del asunto" ${ }^{4},{ }^{48}$ sobre sus creencias fácticas.

\section{UN POSITIVISMO EN CONTRADICCION}

La crítica de Durkheim a Spencer es una buena muestra de su oposición al positivismo clásico por su «moralismo» encubierto, a «los moralistas que deducen su doctrina, no de un principio a priori, sino de algunas proposiciones tomadas de una o varias ciencias positivas como la biología, la psicología, la sociología» y que por ello «califican su moral como científica». ${ }^{49}$ Pero no sólo incluye aquí a Spencer y sus discípulos, vapuleados repetidamente desde las páginas de L'année sociologique; en la misma intención general cabe interpretar sus críticas, antes mentadas, a los socialistas o a Rousseau y aquellos autores que «tienen la costumbre de deducir sus opiniones de aspectos de la condición humana más que del estado de las sociedades»..$^{50}$ No es extraño a la luz de estas críticas su elogio de la obra de Wundt, por sus progresos respecto de las morales precedentes al tomper «definitivamente» con el método poco interesado por «lo que es, sino por lo que en buena lógica debería ser».

47. J. Habermas, «Acerca de los problemas de legitimación», en Problemas de legitimación en el capitalismo tardío, Buenos Aires, 1978, p. 117.

48. N. Rescher, La primacía de la práctica, Madrid, 1980, p. 140.

49. E. Durkheim, De la división..., op. cit., p. 34.

50. E. Durkheim, «Montesquieu, sa part dans la fondation des sciences politiques et de la science des sociétés", en Montesquieu et Rousseau..., op. cit., p. 31.

51. E. Durkheim, «La science positive de la morale en Allemagne», Revue pbilosopbique, núm. 24,1887 , en Textes, op. cit., p. 325 . Es ya desde sus primeros trabajos donde se hace manifiesta su oposición «al método ordinario de los moralistas que, cuando quieren decidir el valor moral de un precepto, comienzan por plantear una fórmula general de la moralidad para confrontarla tuego con la máxima verificadan: De la división..., op. cit., p. 43. 
Estas actitudes para con el "estilo» del positivismo «filasófico» parecen ser poderosos argumentos en favor de la modernidad durkheimiana. Abunda en ello la no excepcional declaración -percibida ambiguamente por algunos de sus comentadores- ${ }^{52}$ de la tarea sociológica como un estudio de los hechos morales, esto es como una metamoral, que se haría cargo del análisis de «las reglas que funcionan ante nuestros ojos (...) lo mismo que la física tiene por objeto los cuerpos tal como existen». ${ }^{53}$

Sin embargo, el repaso anterior de sus tratamientos de los juicios de valor obliga a tnatizar su «modernidad». Sus reprimendas a los kantianos por hacer "de la moral un hecho específico, que escapa a la ciencia», ${ }^{54}$ dificultan interpretar su «ciencia de la moral» como una simple metamoral: más bien parece alimentar la idea de una ciencia moral. Lo que sucede es que Dutkheim a la altura de su tiempo no puede ya proceder como Comte, en base a una "religión positiva» más o menos remotamente «fundada» en la ciencia, no puede oficiar como un positivista «clásico», y por ello intentará obtener las prescripciones prácticas dentro del discurso científico. Ello dificulta la localización de éstas y obliga a proceder analíticamente a la hora de enfrentarse a sus textos. Se trata de localizar donde empieza la trampa lógica a la hora de distinguir entre lo normal y lo patológico; de detectar cuándo introduce el supuesto de que «el hombre quiere vivir», como escribe en un texto temprano donde ya apuntaba a esa otra «solución» de los problemas prácticos, también disfrazada de ciencia y muy preocupante, consistente en «zn estado de salud moral que

52. Véanse las precisiones de J. Duvignaud a los argumentos de Gurvitch sobre las tentaciones durkheimianas de «construir una filosoff́a social y una metamoral», en «Le champ épistémologique de la sociologie à travers Durkheim et L'Année sociologique», introducción a E. Durkheim, Journal Sociologique, París, 1969, p. 11 (se trata de una recopilación de las críticas, comentarios y reseñas de Durkheim). Desde otra perspectiva la relación entre positivismo y ética la subraya D. Duclos, «Projet étique et positivisme dans la démarche sociologique de Durkheim», Cabiers internationaux de Sociologie, vol. IXX, 1981, pp. 85-100.

53. E. Durkheim, Les Regles..., op. cit., pp. 23-24. En De la división..., op. cit., p. 33) escribe, en la misma línea y no sin itonía: «Es posible que la moral tenga algún fin trascendente que la experiencia no puede alcanzar; este asunto corresponde al metafísico. Pero lo cierto ante todo es que se desarrolla en la historia y bajo el imperio de causas históticas, es que tiene una función en nuestra vida temporal. La moral se forma, pues, se transforma y se mantiene por razones de tipo experimental; son razones que la ciencia de la moral trata de determinar.»

54. E. Durkheim, «La science positive de la morale en Allemagne», att. cit. en Textes, op. cit., p. 333. La irreductibilidad del problema ético, tesis de la tradición kantiana, se opone a la "platonización» de los juicios de valor antes mencionada; platonización subrayada por E. Wallwork, Durkbeim, Morality and Milieu, Cambridge (Mass.), 1972, especialmente pp. 27-74. 
sólo la ciencia puede determinar con competencia». ${ }^{55}$ Aunque en ocasiones no se anda con sutilezas, exponiendo con claridad meridiana, entre in. genua y brutal, su programa: «Nosotros pedimos únicamente que el arte moral sea precedido de una ciencia de la moral más metódica que las especulaciones ordinatias de la moral llamada teórica. Toda nuestra tesis puede tesumirse así: para poder determinat qué debe ser moral en un momento determinado en el tiempo, hace falta saber qué es la moral, cómo distinguir lo que es moral de lo que es inmoral, y no se puede responder a esta cuestión si no se han estudiado previamente los fenómenos morales. ${ }^{56}$ Repárese la facilidad con que este espíritu positivista transita del «es» al «debe ser».

EI trato de Durkheim con los valores revela una intención y unos procedimientos clatos: determinar «lo normal y lo patológico», guiar la acción, pero sin caer ni en el "moralismo» ni en la conversión de las ciencias sociales en simples tecnologías. Para ello intentará asirse al único instrumento capaz de garantizar, en su opinión, que aquellos deseos no van a caer en el misticismo, la ciencia. Para una idea de razón como la que comparte Durkheim, la positivista, que agota su ejercicio en la ciencia, sólo caben dos tratamientos de los valores y la ética: la «moderna», la más frecuente, su simple exclusión del ámbito de la razón condenándola al ejercicio místico, o la incorporación a la razón, esto es, a la ciencia, con el consiguiente resultado de su falseamiento.

A Durkheim - $\mathrm{y}$ habría que decir a su época y país-57 la primera opción le repugna e intenta, con su obra, exorcizarla: «De este modo desaparece la antítesis que se trata de establecer a menudo entre la ciencia y la moral, argumento temible donde los místicos de todos los tiempos quisieron hacer zozobrar la tazón humana. Para regular nuestras relacio. nes con los hombres no es necesatio recurtir a otros medios que los que nos sirven para regular nuestras relaciones con las cosas; la reffexión me-

55. E. Durkheim, De la división..., op. cit., p. 35.

56. E. Durkheim, reseña del libro de S. Deploige, «Le conflit de la morale et de la sociologie», aparecida en L'Année sociologique, 1909-1912, París, 1913, p. 327.

57. Mientras se ha escrito mucho sobre «la transición» al positivismo moderno en la tradición anglosajona (la reacción contra el hegelianismo de McTaggart, en Cambridge, por parte de Moore y, a su través, Russell; la conformación del círculo de Viena), en lo que respecta a la pattia del positivismo, tal proceso apenas ha merecido atención. Una razón no menot para entender este silencio quizá habría que buscarla en que bien tempranamente se da, en autores que desde una u otra perspectiva han sido calificados de positivistas, una necesidad de escapar al escepticismo -la otra cara del «sólo acepta la ciencia como razón»- que no carece de tonos poco «presentables», sea en forma hegeliana (Taine, J. E. Renan), «espiritualista» (Lacheliet, L. Weber) e, incluso, inmoralista (Guyan). 
tódicamente empleada basta en uno y otro caso. La ciencia de la moral reconcilia a la ciencia con la moral.» ${ }^{58}$ No existen dudas de su apuesta por la segunda opción, por la inclusión —encubierta- de los valores en la ciencia. Pero aquellos son inquilinos incómodos para ésta, tan incómodos que acabarán por desalojar al propietario. Es en un debate - tal vez por el acaloramiento propio de la circunstancia - donde esta tesis la resume Durkheirn con mayor claridad: «La única razón por la cual estáis legitimados para teivindicar, aquí como en otra parte, el derecho a intervenir y elevaros por encima de la realidad moral histórica en vista a reformarla, no es mi razón, ni la de ustedes; es la sazón humana, impersonal, que no se ha realizado verdaderamente más que en la ciencia. Del mismo modo que la ciencia de las cosas físicas nos permite enderezarlas, la ciencia de los hechos morales nos pone en condiciones de dirigir, de enderezar, de corregir el curso de la vida moral. Pero esta intervención de la ciencia tiene por objetivo sustituir el ideal colectivo de hoy, no por un ideal individual, sino por un ideal igualmente colectivo, y que exprese no una personalidad particular, sino a la colectividad mejor comprendida. $\$^{59}$

Caben pocas dudas, pues, de la necesidad de revisar la imagen tópica del «cofundador» - con Weber- de la sociología, según la cual Durkheim iniciaría la emancipación de esta disciplina de sus orígenes prácticos al intetesarse -y definir su objeto- únicamente por los hechos sociales. Seguramente tal revisión nos mostraría una obra menos rigurosa analíticamente de lo que se presenta; pero también más viva, más digna de ser releída y no sólo como «testimonio histórico» o como materia de «reinterpretación», sino para aprender (ahí están sus «premoniciones» de los temas qưe arrancan en los veinte: la crítica de la razón instrumental, la ingeniería social, etc.) sobre las tensiones irresolubles de una moderna razón que en su vertiente positivista o por la mística - su otta cara, como percibe Durkheim- dibujan el hoxizonte intelectual occidental desde el siglo pasado. Para aptender, como también sucede con el alemán, a inquietarse.

58. E. Durkheim, De la división..., op. cit., p. 36. Curiosamente, algún conentarista de Durkheim ha expuesto con claridad esta tesis haciendo suyas las palabtas. textuales de éste: «El constante cuidado que muestra Durkheim por evitar el misticismo, abismo que amenaza la razón humana, por refutar con los resultados mismos de sus investigaciones a quienes repiten que en materia de moral la ciencia ha hecho bancartota, de oftecer, en fin, a la consciencia un fundamento empírico establecido por la observación positiva. En este sentido se podría sostener que la voluntad de Durkheim es la de hablar, también en materia de moral, un lenguaje de sabio espe. cializado, no un lenguaje de filósofo.» C. Bouglé, prefacio a E. Durkheim, Sociologie et Pbilosophie, op. cit., p. vII.

59. E. Durkheim, «Réponses aux objections», a «Détermination du fait moral», art. cit., en Sociologie et Pbilosopbie, op. cit., pp. 95-96. 